\title{
The effects of luteinizing hormone ablation/replacement versus steroid ablation/replacement on gene expression in the primate corpus luteum
}

\author{
Cecily V. Bishop 1,3, Jon D. Hennebold ${ }^{1,2}$, and Richard L. Stouffer ${ }^{1,2}$ \\ 'Division of Reproductive Sciences, Oregon National Primate Research Center, 505 NW I85th Avenue, Beaverton, OR 97006, USA \\ ${ }^{2}$ Department of Obstetrics and Gynecology, Oregon Health \& Science University, Portland, OR 97239, USA \\ ${ }^{3}$ Correspondence address. E-mail: bishopc@ohsu.edu
}

\begin{abstract}
This study was designed to provide a genome-wide analysis of the effects of luteinizing hormone (LH) versus steroid ablation/ replacement on gene expression in the developed corpus luteum $(C L)$ in primates during the menstrual cycle. On Days $9-1$ I of the luteal phase, female rhesus monkeys were left untreated (control) or received a $\mathrm{GnRH}$ antagonist Antide (A), $\mathrm{A}+\mathrm{LH}, \mathrm{A}+\mathrm{LH}+$ the $3 \beta$-hydroxysteroid dehydrogenase inhibitor Trilostane (TRL) or $A+L H+T R L+$ a progestin R5020. On Day 12 of the luteal phase, $C L$ were removed and samples of RNA from individual CL were hybridized to Affymetrix ${ }^{T M}$ rhesus macaque total genome microarrays. The greatest number of altered transcripts was associated with the ablation/replacement of $\mathrm{LH}$, while steroid ablation/progestin replacement affected fewer transcripts. Replacement of LH during Antide treatment restored the expression of most transcripts to control levels. Validation of a subset of transcripts revealed that the expression patterns were similar between microarray and real-time PCR. Analyses of protein levels were subsequently determined for two transcripts. This is the first genome-wide analysis of $\mathrm{LH}$ and steroid regulation of gene transcription in the developed primate CL. Further analysis of novel transcripts identified in this data set can clarify the relative role for $\mathrm{LH}$ and steroids in CL maintenance and luteolysis.
\end{abstract}

Key words: corpus luteum / luteinizing hormone / microarray / steroids / progesterone

\section{Introduction}

Corpora lutea $(\mathrm{CL})$ appear very similar, in terms of structure, function and regulation, between old-world monkeys (rhesus macaques) and humans. Humans and macaques have similar length menstrual cycles (luteal phases of the cycles are approximately the same length), neither relies on a uterine signal to induce luteolysis in non-gravid cycles and both exhibit an absolute requirement for luteinizing hormone (LH) from the anterior pituitary to maintain luteal structure-function (Stouffer, 2006).

Treatment of rhesus macaques with an antagonist of gonadotrophin-releasing hormone $(\mathrm{GnRH}$; Antide, to inhibit $\mathrm{LH}$ production) results in rapid destruction of developed $\mathrm{CL}$ [as evidenced by a dramatic drop in progesterone $(P)$ secretion], but the functional lifespan of these $C L$ can be rescued by pulsatile administration of exogenous LH (Duffy et al., 1999b). Primate CL are remarkably sensitive to local LH levels as macaque luteinized granulosa/luteal cells respond to acute $\mathrm{LH}$ stimulation by rapidly secreting $\mathrm{P}$ in vitro, and $\mathrm{LH}$ pulses are entrained to $\mathrm{P}$ pulses by mid-luteal phase in vivo (Molskness et al., 199I; Stouffer, 2003). It is generally accepted that LH exerts its effects on targets, i.e. luteal cells, via the $\mathrm{LH}$ receptor (LHR), a seven transmembrane domain G-protein-coupled receptor capable of activating adenylate cyclase in the ovary (Benyo and Zeleznik, 1997; Zeleznik and Somers, 1999; Priyanka and Medhamurthy, 2007), and in other cells/tissues (Ascoli et al., 2002). However, the exact mechanism(s) by which $\mathrm{LH}$ exerts its luteotropic effects on the primate $C L$ have yet to be elucidated.

Local autocrine/paracrine factors produced in response to LH may also be important in controlling $C L$ structure-function. For example, it is hypothesized that locally produced $\mathrm{P}$ is the primary luteotropin in

(C) The Author 2009. Published by Oxford University Press on behalf of the European Society of Human Reproduction and Embryology. All rights reserved.

For Permissions, please email: journals.permissions@oxfordjournals.org

The online version of this article has been published under an open access model. Users are entitled to use, reproduce, disseminate, or display the open access version of this article for non-commercial purposes provided that: the original authorship is properly and fully attributed: the Journal and Oxford University Press are attributed as the original place of publication with the correct citation details given: if an article is subsequently reproduced or disseminated not in its entirety but only in part or as a derivative word this must be clearly indicated. For commercial re-use, please contact journals.permissions@oxfordjournals.org 
the primate $C L$, and alone may be sufficient to sustain luteal function, i.e. the so-called 'Rothchild hypothesis' (Rothchild, 198I). Treatment of rhesus monkeys during the mid-luteal phase with Trilostane (TRL), an inhibitor of $3 \beta$-hydroxysteroid dehydrogenase ( $3 \beta-H S D)$, results in onset of premature luteolysis within 4 days of treatment (Duffy et al., 1994). Luteal phase length is reduced by approximately half, whereas endogenous $\mathrm{LH}$ levels remain relatively unchanged following TRL administration. The so-called 'genomic' progesterone receptors (PGRs; ligand-activated transcription factors) are present in macaque luteal cells and co-localize with $3 \beta-\mathrm{HSD}$, supporting the premise of the Rothchild hypothesis (Stouffer and Duffy, 1995). But, receptors for other sex steroids [e.g. estrogen receptor $\beta$ (ESR2) and androgen receptor $(A R)]$ as well as mRNAs for putative membrane-associated steroid receptors were also detected in primate $C L$ (Duffy et al., 1999a, 2000; Engmann et al., 2006). Genomic steroid hormone receptors are ligand-activated transcription factors that bind to regulatory elements on DNA with the assistance of several co-factors to modify gene transcription (Lonard and O'Malley, 2005). Thus, the actions of $\mathrm{LH}$ on $\mathrm{CL}$ structure-function are likely a composite of direct $\mathrm{LH}$ receptor-mediated effects and indirect effects resulting from LH-regulated local factors, e.g. steroids including P.

To investigate both the direct and indirect (via local steroids including $\mathrm{P}$ ) effects of $\mathrm{LH}$ on the primate $\mathrm{CL}$ during the menstrual cycle, an in vivo model was developed in which ablation and replacement of $\mathrm{LH}$ (Duffy et al., 1999b) and steroid ablation/progestin replacement could be performed in rhesus monkeys during the same experimental protocol (Young and Stouffer, 2004). Previous ablation/replacement experiments on the primate $C L$ focused primarily on the effects of $\mathrm{LH}$ versus $\mathrm{P}$ on individual gene families, including proteases and caspases involved in tissue reorganization (Young et al., 2002, 2004; Young and Stouffer 2004; Peluffo et al., 2005).

Recently, attempts were made to broadly evaluate $\mathrm{LH}$ regulation of genes in the macaque CL (Yadav et al., 2004; Xu et al., 2005). Xu et al. (2005) either left rhesus monkeys untreated or administered a single bolus of Antide in the mid-luteal phase, the $C L$ were removed and total cDNA hybridized to a limited (I 600 transcripts) human spotted array. The resulting data successfully identified a novel group of genes, including the corticotropin-releasing hormone $(\mathrm{CRH})$ /urocortin (UCN)-receptor-binding protein system, that appear to be involved in the maintenance of $C L$ structure/function (Xu et al., 2007). Yadav et al. (2004) used the $\mathrm{GnRH}$ antagonist Cetrorelix (C), administered to bonnet monkeys in the mid-luteal phase, to identify changes in mRNA transcripts by differential display. Seven transcripts, including mRNA for low-density lipoprotein (LDL) receptor, were identified as changing in expression after LH withdrawal (Yadav et al., 2004).

While these approaches were successful in identifying novel gene regulation by $\mathrm{LH}$ in the $\mathrm{CL}$, further opportunities now exist for global (genome-wide) evaluation of gene activities in macaque tissues (Noriega et al., 2007; Parent et al., 2008) including the rhesus CL (Bogan et al., 2008b) using the Affymetrix ${ }^{\text {TM }}$ Rhesus Macaque Genome Expression Array. Building on these validated studies, we utilized the rhesus array to further identify changes in gene expression in the macaque $\mathrm{CL}$ in response to $\mathrm{LH}$ and steroid ablation/replacement as described earlier. It was expected that $\mathrm{LH}$-dependent changes in gene expression (directly regulated by $\mathrm{LH}$ ) could be contrasted and compared with changes in the expression of genes that were steroid (especially P) dependent (indirectly regulated by LH).

\section{Materials and Methods}

The studies were performed at the Oregon National Primate Research Center (ONPRC) on the West Campus of Oregon Health \& Science University (OHSU). All procedures and protocols were approved by the ONPRC/OHSU Animal Care and Use Committee, in accordance with the National Institute of Health $(\mathrm{NIH})$ Guidelines for Care and Use of Laboratory Animals. Adult, female rhesus macaques (Macaca mulatta) exhibiting regular menstrual cycles were selected for the study and were under the direct care of the ONPRC Division of Animal Resources (DAR).

Monkeys $(n=22)$ received one of the following treatments for 3 days beginning on Day 9 of the luteal phase (mid-luteal phase, the time of peak $\mathrm{CL}$ function). Some females were left untreated to establish gene/ protein expression in normal $\mathrm{CL}$ (control group; $n=4$ ). Alternatively, ablation of $\mathrm{LH}$ was accomplished by treating females with a $\mathrm{GnRH}$ antagonist [Antide obtained from the Contraceptive Development Branch, Center for Population Research, National Institute of Child Health and Human Development (NICHD), $3 \mathrm{mg} / \mathrm{kg}$ once per day, $n=5$ ]. This treatment significantly lowers LH and P levels within I day, with baseline levels present by the end of the experimental period (Duffy et al., 1999b). Recombinant human $\mathrm{LH}$ (40 IU, three times daily) was also administered in a pulsatile manner $(\mathrm{A}+\mathrm{LH} ; n=4)$, which returns systemic $\mathrm{LH}$ and $\mathrm{P}$ to control levels (Duffy et al., 1999b). In addition, steroid production by the $\mathrm{CL}$ in response to $\mathrm{LH}$ replacement was blocked by oral administration

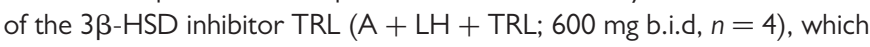
suppresses systemic $P$ levels and induces premature luteolysis at this dosage and duration of treatment in rhesus monkeys (Duffy et al. 1994). Actions of $\mathrm{P}$ were restored in a subset of TRL-treated animals by treatment with a synthetic progestin, R5020 (A + LH + TRL + R5020; $2.5 \mathrm{ng} / \mathrm{ml}$ once per day, $n=5$ ), at a dosage and duration that prevents the indices of luteolysis brought on by TRL treatment in macaque monkeys (Young and Stouffer, 2004). Following the 3-day treatment interval, $C L$ were surgically removed and half of each tissue was individually processed for total RNA, and the other half for total protein as described previously (Peluffo et al., 2005). Anesthesia of animals and lutectomy were performed by the surgical veterinary staff (DAR, ONPRC) as described previously (Duffy et al., 2000).

\section{Microarray analysis and real-time PCR validation}

All rhesus macaque genome arrays were processed by the OHSU Affymetrix Microarray Core (AMC), OHSU. The AMC performed the RNA expression profiling, amplification and hybridization of samples (http:// www.ohsu.edu/gmsr/amc/amc_technology.html\#assay). Following data normalization using the robust multichip average algorithm, the web-based GeneSifter(C) software (http://www.genesifter.net/web/) was used to identify transcripts from $\log _{2}$-transformed data that significantly changed expression between treatment groups by pairwise comparison analysis ( $t$-test, $P<0.05)$, and for the entire experimental group by multiple comparison analysis procedures (one-way ANOVA, $P<0.05$; see http:// www.genesifter.net/web/webinars.php for further explanation of analytical methods by GeneSifter(C). The Affymetrix ${ }^{T M}$ Rhesus Genome Array contains 52024 rhesus probe sets for approximately 47000 rhesus transcripts, plus several control probe sets; array design is based on the Baylor School of Medicine's rhesus macaque whole-genome shotgun assembly and GenBank ${ }^{\circledR}$ sequence-tagged sites (STSs), expressed sequence tag and mRNA sequences (http://www.affymetrix.com/ support/technical/datasheets/rhesus_datasheet.pdf). There are multiple probes sets (transcripts) for individual gene products on this array (Spindel et al., 2005). Therefore, microarray data will be referred to as 
'transcripts', whereas real-time PCR data will be referred to as 'mRNA' values.

Data files were submitted to the Gene Expression Omnibus (www. ncbi.nlm.nih.gov/geo: series GSEI2 28I). To validate the microarray results, selected genes were analyzed by real-time PCR to quantify changes in mRNA levels that occur following $\mathrm{LH}$ and/or P ablation/replacement. The real-time PCR probes were designed as described previously (Xu et al., 2006) and labeled with the $5^{\prime}$ reporter dye FAM and the $3^{\prime}$ quencher dye MGBNFQ. Sequences for real-time probes and primers are listed in Table I, along with gene identifiers. All real-time studies were performed and analyzed as reported previously ( $\mathrm{Xu}$ et al., 2006). The data were subjected to one-way ANOVA by the use of SigmaStat $($ software (Version 2.0). When significant $(P<0.05)$, differences between treatment groups were analyzed by pairwise multiple comparison procedures (Tukey test or Student-Newman-Keuls method as appropriate).

\section{Western blot analysis}

Immunoblot (western blot) analysis was performed to permit comparison of the patterns of protein levels of two selected gene products versus their mRNA levels in individual CL. Electrophoresis was performed using gradient gels (10-20\% liner with $4 \%$ stacking gel; BioRad Laboratories, Hercules, CA, USA) with $20 \mu \mathrm{g}$ of protein in denaturing SDS loading buffer (3\% SDS, 7 mM EDTA, 7 mM EGTA, 7\% glycerol, 0.36 M Tris, $3.6 \mathrm{mM}$ DTT and $3.6 \%$ bromophenol blue) per individual sample.

After electrophoresis, proteins were transferred to Immun-Blot ${ }^{\mathrm{TM}}$ PVDF membranes $\left(0.2 \mu \mathrm{M}\right.$; BioRad) overnight at $4^{\circ} \mathrm{C}$. Membranes were blocked with a neutral protein $(3 \% \mathrm{NFM})$ at $4{ }^{\circ} \mathrm{C}$ overnight and then incubated with the following primary antibodies according to the manufacturer's protocols: mouse anti-human secreted frizzled related protein-4 (SFRP4) whole sera antibody (final dilution 1:1000; Abnova/Affinity Bioreagents H00006424-A0I) or rabbit anti-human steroidogenic acute regulatory (StAR) protein (final concentration I $\mu \mathrm{g} / \mathrm{ml}$; Fisher/Affinity Bioreagents PAI-560). All horseradish peroxidase-labeled secondary antibodies were from the same source (Zymed Laboratories, Invitrogen Corp., Carlsbad, CA, USA), specific to the host animal of the primary antibody, and used at a final dilution of 1:2000.

For the quantification of protein levels from individual $\mathrm{CL}$, a luminescent signal was generated using western blotting luminol reagent (Santa Cruz Biotechnology, Inc., Santa Cruz, CA, USA) and detected with Kodak X-OMAT film (Eastman Kodak Co., Rochester, NY, USA). Densitometry analysis was performed using a gel documentation system and Quantity One software (Bio-Rad). To quantify protein levels, the blots were stripped by a gentle method (successive PBS and TBST washes, Abcam Inc., Cambridge, MA, USA) to remove all antibodies. This method was confirmed for each antibody by incubation of stripped blots with only the secondary antibody and then developed for any luminescent signal as described earlier. Blots were then blocked again overnight and re-probed for $\beta$-actin levels (Tesone et al., 2005) by incubation with the primary antibody rabbit anti-human $\beta$-actin $(0.8 \mu \mathrm{g} / \mathrm{ml}$; Abcam ab8227), and secondary antibody as before. All data were subject to one-way ANOVA (similar to real-time PCR data) and are presented as the intensity of protein of interest: $\beta$-actin intensity. Because of high background to signal ratio for SFRP4 blots containing +TRL and +R5020 samples, for both $\beta$-actin and SFRP4 samples, background intensity was subtracted from average intensity for all bands (regardless of treatment group) before normalization for SFRP4 expression.

For presentation of western blot data, samples from individual $\mathrm{CL}$ were pooled by treatment group, and then pooled samples underwent electrophoresis and transfer as stated earlier for the detection of each protein of interest (StAR, SFRP4 and $\beta$-actin). Following electrophoresis and protein transfer to PVDF membranes, StAR and $\beta$-actin blots were developed via the WesternDot ${ }^{\text {TM }} 625$ Western Blot Kit (Invitrogen, Molecular Probes) with the aforementioned primary antibodies according to the manufacturer's protocol; SFRP4 was developed as described earlier.

\section{Results}

Normalized data files for individual arrays have been uploaded to the National Center for Biotechnology Information's Gene Expression Omnibus gene expression repository (http://www.ncbi.nlm.nih.gov/ geo/ Series GSEI228I). Of the more than 47000 transcripts represented on the rhesus genome arrays, the multiple comparison analysis of GeneSifter(C) identified $\sim 2 \%$ of all transcripts on the array as changing in expression $\geq 2$-fold between various treatments (one-way ANOVA, $P<0.05$ ); these were then analyzed by the cluster analysis algorithm of GeneSifter(C) (for further description of cluster analysis, see http://www.genesifter.net/web/resources_cluster.php, and http://www.statsoft.com/textbook/stcluan.html for a description of the cluster analyses performed by the GeneSifter(C) software). The results are presented as a heat map showing relative levels of expression in Fig. IA. The heat map is divided into two regions: region I (above the line) shows transcripts whose levels increased (red) above controls following treatment with Antide, and region 2 depicts transcripts whose levels decreased (green) with Antide treatment. The majority of transcripts were in the latter region, i.e. levels decreased in expression following Antide treatment. Most transcripts in both regions were restored to near-control levels by LH replacement (see Table II for examples of transcripts not restored by LH replacement, which compares the transcripts that differ significantly between the control and the Antide+LH groups). Many, but not all, of the Antide-sensitive transcripts appear to be affected similarly (either decreased or increased) by steroid withdrawal (TRL), but several of these changes were not as pronounced. Treatment with R5020 reversed many of the effects of TRL, but not necessarily to the level observed with LH replacement.

These changes in transcript expression are depicted in Fig. IB as a pairwise comparison of the number of transcripts differing between treatment groups. The largest number of differentially expressed transcripts was associated with LH ablation/replacement, while steroid ablation/replacement affected fewer transcripts (Fig. IB). Hierarchical cluster analysis of all treatment groups by GeneSifter(C) indicated that the Control and $\mathrm{A}+\mathrm{LH}$ groups were similar in gene expression, whereas the Antide group was most related to the $A+L H+T R L$ and $\mathrm{A}+\mathrm{LH}+\mathrm{TRL}+\mathrm{R} 5020$ groups. Because a relatively small number of transcripts differed $\geq 2$-fold between the control and $A+L H$ groups $(n=36$, Fig. IB), the A $+\mathrm{LH}$ group can be considered a separate 'control' for the steroid ablation/replacement groups for the purpose of further analysis. Pathways significantly [as determined by z-score (Doniger et al., 2003) and ontology abundance] affected by treatments ( $\geq 2$-fold) are depicted by known gene ontologies in Table III. Many of these significant ontologies are associated with the production of steroids and steroid precursors (e.g. sterol biosynthetic processes and cholesterol biosynthetic processes), and a number are related to the immune system/response (immunoglobulin production, regulation of $\mathrm{B}$ cell activation, and others). 
Table I Real-time PCR primer and probe sequences used to validate microarray expression

\begin{tabular}{|c|c|c|c|c|}
\hline Gene $^{a}$ & NCBI Accession Number & Forward Primer $\left(5^{\prime}-3^{\prime}\right)$ & Probe $\left(5^{\prime}-3^{\prime}\right)$ 6FAM-Sequence-MGBNFQ & Reverse Primer $\left(5^{\prime}-3^{\prime}\right)$ \\
\hline $\mathrm{MHCl}$ & U84789 & CAGATAGATAAGGCGGGAGCTACT & CAGTGACAGTTCCC & GCCGTGAGAGACACATCAGAAC \\
\hline SFRP4 & NM_00I032962 & CTGCGAGCCCCTCATGAA & CACAGCTGGCCCGAA & GTCATAGACGGGCAGCTCATC \\
\hline CCL3 & BV209119 & GGCCTGCTGTAGGCAGTCAT & CAGACTGACCAATGTGTATC & ACAGCCCTGACCAAAAGCAT \\
\hline CAT & NM_001752 & TCCATTCGATCTCACCAAGGT & CAA GGACTACCCTCTCAT & CCGGTTTAAGACCAGTTTACCAA \\
\hline StAR & BV208869 & GTGCGTGTGTACAAGGCAGAA & CGGCAGCCCTCTG & GGTGTTGCTGTGCAGTGAATG \\
\hline ADAMTS-5 & XM_00II 03439 & TTCATGTTTCCCTCAGATAGTGATG & ACACATGTCATAGAAACAA & TGGTTTATTTGCTCTAAGCCCTCTA \\
\hline MMP-9 & XM_00I I0487I & AGGCGCTCATGTACCCTATGTAC & CCССССТTGCATAAG & TGCCGGATGCCATTCAC \\
\hline MMP-19 & XM_00IIIII542 & TGGCCCCCAACTCCATT & TGTCTTAGACAGCCCTTC & ACCATTGACCTCCAGAAAAGAGAT \\
\hline CASP2 & NM_032982 & GCACTGAGGGAGACCAAGCA & TCACCACCCTTTCCGGGCTTCAG & CACAGCTCAACGGTGGGAGTA \\
\hline ILIRN & U65590 & TGGCACTTGGAGACGTGTATG & CCTCGGCCTGTCTC & CGAGTCTTTTTTTCCTGCTCTGAA \\
\hline AHRIP & NM_003977 & TCCAAAAACGTGTGATACAGGAA & CTCCCGGACTTTC & TAGTGGAACGTGGCCTTGGT \\
\hline ARNT2 & BV208380 & CCAGTCCCAGGGAATGAATG & CTCCCGGCAGCACT & CACGTTCTCGCATAGCTTATGG \\
\hline VEGF & M2728I X15997 & ACGAAGTGGTGAAGTTCATGGA & TCAGCGCAGCTACT & CTCATCAGGGTACTCCTGGAAGA \\
\hline PRLR & NM_000949 & AGCTGAGTGGGAGACCCATTT & AAACAGAGTTTAAGATTCTC & GCGAACCTGGACAAGGTATTTC \\
\hline CRHBP & NM_00I882 & GACAGACCCCAACCTCTTTCC & CCCTGGTCGTTCCAC & TGGAGAAGCTGCAGTTTCGA \\
\hline INHBA & BVI66389 & AGAGCACCTGGCACGTCTTC & CAGCATCCAGCGGTT & ACGTCCAGGGAGCTTTTTCC \\
\hline SC4MOL & $A B \mid 69840$ & TGGAGTGTAGCGGCACAATC & CGGCTCACTGCAAC & GGAGGCTGAGGCAGGAGAAT \\
\hline LOC693394 & XM_00I08I982 & CACGTCATCGACTACATCTTGGA & CCTGGACTCGCATCC & TCTGGTGATGGAGGCTGACA \\
\hline ESR2 & AB006589 & TCAGTTGAGGTCAGGAGTTTGAAA & CAACATGGCGAAACC & ACCACCATGCCTGGCTAATT \\
\hline AR & NM_0010329II & GCAGGCAAGAGCACTGAAGATA & TGCTGAGTATTCCCC & CCTTTGGTGTAACCTCCCTTGA \\
\hline PGR & XM_001095317 & CATGTCAGTGGGCAGATGCT & TATTTTGCACCTGATCTAA & ATTCTTTCATCCGCTGTTCATTC \\
\hline PGRMCI & XM_00II 00639 & CCAGGACCCCCGCATAC & CATGGCCATCAACG & TTTGGTCACGTCGAACACCTT \\
\hline
\end{tabular}

a'Based on NCBI Entrez Gene Terminology. 


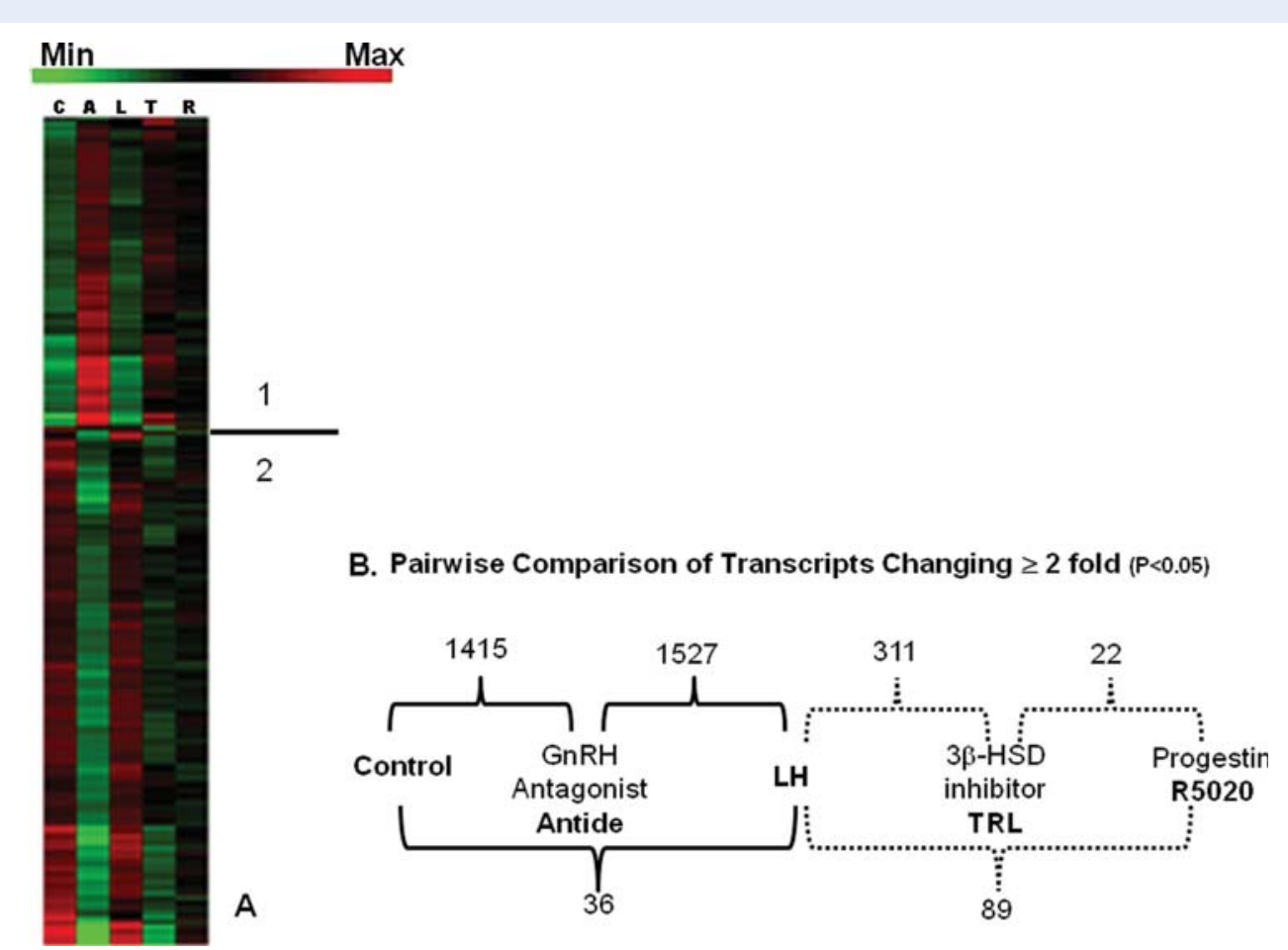

Figure I (A) Cluster analysis by multiple comparison procedure of GeneSifter $(C)$ of all transcripts whose levels significantly $(P<0.05)$ changed in expression $\geq 2$-fold when compared with control CL. The heat map indicates the relative levels of the expression of each transcript, with red indicating increased expression and green indicating decreased expression. The line separates the two regions of different transcript expression: I: increasing expression with Antide treatment; 2: decreasing expression with Antide treatment. C, control; A, Antide; L, A + LH; T, A + LH + TRL; R, A + LH + $T R L+R 5020$. (B) Summary of pairwise comparison analysis of the number of transcripts identified by GeneSifter(C) as significantly changing expression $\geq 2$-fold (Student's $t$-test, $P<0.05$ ) between indicated treatment groups. Comparisons between complimentary ablation/replacement groups are indicated on the top, whereas pairwise comparisons between control and $A+L H$, or $A+L H$ and $A+L H+T R L+R 5020$ treatments are depicted below. For example, 1415 transcripts differ significantly between the control and Antide treatment groups, whereas only 36 differ significantly between the control and Antide $+\mathrm{LH}$ treatment groups. The number of transcripts whose expression differs between control, Antide and $\mathrm{A}+\mathrm{LH}$ groups (black brackets) are greater than those between $\mathrm{A}+\mathrm{LH}, \mathrm{A}+\mathrm{LH}+\mathrm{TRL}$ and $\mathrm{A}+\mathrm{LH}+\mathrm{TRL}+\mathrm{R} 5020$ groups (dashed brackets).

Several genes $(n=22)$, representing transcripts identified from the microarray data set as expressed in the macaque $C L$, were chosen for validation by real-time PCR. These included novel genes with respect to luteal function, steroid hormone receptors, previously determined $\mathrm{LH}$ - and/or steroid-regulated genes, plus 'negative control' transcripts that did not change in expression between groups. Table IV lists all validated genes and summarizes the results of microarray expression analysis and one-way ANOVA values for real-time PCR data. The table is divided into examples of gene transcripts whose levels were (i) not altered by treatments (not regulated), (ii) LH-regulated independent of steroid influence and (iii) LH-regulated in a $\mathrm{P}$ or (iv) other steroid-dependent manner. Typically, the patterns of mRNA levels determined by real-time PCR resembled those from microarray analysis (Table IV).

An example of a novel gene identified by microarray as being $\mathrm{LH}$-regulated in the primate $\mathrm{CL}$ is interleukin I receptor antagonist (ILIRN), depicted in Fig. 2. The ILIRN gene belongs to the "negative regulation of immune system process' ontology based on known Kyoto Encyclopedia of Genes and Genomes-KEGG pathways (similar to Table III, which displays the number of transcripts with known gene ontology pathways); many of the transcripts in this ontology, including ILIRN, were mainly affected by LH ablation/replacement, and to a lesser extent, by steroid ablation/P replacement (Fig. 2A). Results from real-time PCR analysis were comparable with those provided by microarray analysis (Fig. 2B); ILIRN mRNA levels increased following Antide treatment, but this effect was prevented by $L H$ replacement. Treatment with TRL with or without R5020 replacement was without effect.

Regulated members of the 'steroid biosynthetic process' ontology, based on known KEGG pathways (similar to the results from Table III), and two validated genes from this category are presented in Fig. 3. Most of these transcripts are regulated similarly by $\mathrm{LH}$ and steroid ablation (Fig. 3A) in that transcript levels declined with Antide or TRL treatment. While $\mathrm{LH}$ replacement typically prevented the decline induced by Antide, progestin replacement with R5020 was less effective in preventing TRL's effects, except in some instances (e.g. STARD4, CYPI9AI). Results from real-time PCR assays of the prolactin receptor (PRLR; Fig. 3B) and sterol-C4-methyl oxidase-like (SC4MOL; Fig. 3C) mRNAs were comparable with the results obtained by microarray. Levels of both mRNAs were decreased by Antide treatment, and LH replacement maintained levels similar to control. Likewise, TRL treatment resulted in mRNA levels similar to 
Table II Transcripts not restored to control levels by LH replacement of Antide-treated CL $(\geq 2$-fold differences $P<0.05)$

\begin{tabular}{|c|c|c|c|}
\hline Affymetrix Gene Transcript & $\begin{array}{l}\text { NCBI Accession } \\
\text { No. }\end{array}$ & $\begin{array}{l}\text { Antide } \\
\text { Effect }^{\mathrm{a}}\end{array}$ & Ratio $^{\text {b }}$ \\
\hline Mamu-DRB mRNA for major histocompatibility complex class II, partial cds, clone:R00205DR09 & $A B \mid I 2035$ & Down & 4.7 \\
\hline Pre-B-cell colony enhancing factor I & AA873350 & Down & 4.3 \\
\hline Nuclear receptor subfamily 4 , group $A$, member I & NM_002135 & Down & 4.3 \\
\hline Prostaglandin F receptor (FP) & NM_000959 & Down & 4.3 \\
\hline $\begin{array}{l}\text { gDNA.Hs2.894|8.2.SI FEA }=\text { UI33PSR GEN }=\text { PTGFR DEF = Orthologous to I555097_a_at } \\
\text { prostaglandin F receptor (FP) }\end{array}$ & BC035694 & Down & 4.2 \\
\hline Pre-B-cell colony enhancing factor I & BF5755।4 & Down & 3.9 \\
\hline Low density lipoprotein receptor (familial hypercholesterolemia) & Al861942 & Down & 3.6 \\
\hline$V$-fos FBJ murine osteosarcoma viral oncogene homolog & BC004490 & Down & 3.4 \\
\hline $\begin{array}{l}\text { gi:47777222 DEF = TUBAI_I2 I4 Rhesus macaque genomic DNA Macaca mulatta STS genomic clone } \\
\text { MMA I2 I4, sequence tagged site. GEN = TUBAI PROD=tubulin, alpha I }\end{array}$ & & Down & 3.3 \\
\hline Low density lipoprotein receptor (familial hypercholesterolemia) & NM_000527 & Down & 3.3 \\
\hline Hypothetical protein LOCI29293 (LOCI29293), mRNA & AA00536I & Down & 3.2 \\
\hline $\begin{array}{l}\text { gDNA.Hs. I06635.0.S2 FEA = UI33PSR GEN = PIPPIN DEF = Orthologous to 20998I_at RNA-binding } \\
\text { protein pippin }\end{array}$ & AL023553 & Down & 3.0 \\
\hline Transcribed locus & Al248760 & Down & 2.9 \\
\hline Pre-B-cell colony enhancing factor I & BC02069I & Down & 2.7 \\
\hline Pre-B-cell colony enhancing factor I & NM_005746 & Down & 2.4 \\
\hline Pre-B-cell colony enhancing factor I & BF5755I4 & Down & 2.4 \\
\hline Endothelial cell-specific molecule I & NM_007036 & Down & 2.4 \\
\hline $\begin{array}{l}\text { Similar to nicotinamide phosphoribosyltransferase (NAmPRTase) (Nampt) (Pre-B-cell colony-enhancing } \\
\text { factor I homolog) (PBEF) }\end{array}$ & CB229989 & Down & 2.4 \\
\hline DIS3 mitotic control homolog (S. cerevisiae)-like 2 & Al9357।7 & Down & 2.4 \\
\hline $\begin{array}{l}\text { gi:47776579 DEF }=\text { EHD3_6I3 Rhesus macaque genomic DNA Macaca mulatta STS genomic clone } \\
\text { MMA6I3, sequence tagged site. GEN }=\text { EHD3 PROD }=\text { EH-domain containing } 3\end{array}$ & & Down & 2.3 \\
\hline zinc finger, DHHC-type containing 19 & NM_I44637 & Down & 2.2 \\
\hline complement component 4B (Childo blood group) & NM_000592 & Down & 2.2 \\
\hline Transcribed locus & Al873273 & Down & 2.2 \\
\hline Aminolevulinate, delta-, synthase I & NM_000688 & Down & 2.2 \\
\hline Transcribed locus, strongly similar to NP_057696.2 mitochondrial solute carrier protein [Homo sapiens] & H6970I & Down & 2.0 \\
\hline Dual specificity phosphatase I & AA530892 & Down & 2.0 \\
\hline Amine oxidase, copper containing 2 (retina-specific) & NM_009590 & Down & 2.0 \\
\hline $\begin{array}{l}\text { Similar to HLA class I histocompatibility antigen, A-74 alpha chain precursor (MHC class I antigen A*74) } \\
(\text { Aw-74) (Aw-19) }\end{array}$ & AFI5740I & Up & 8.4 \\
\hline Neuronal pentraxin I & NM_002522 & Up & 4.1 \\
\hline Serpin peptidase inhibitor, clade E (nexin, plasminogen activator inhibitor type I), member I & NM_000602 & Up & 3.5 \\
\hline $\begin{array}{l}\text { gi:477767 I2 DEF }=\text { HP_I } 43 \text { Rhesus macaque genomic DNA Macaca mulatta STS genomic clone MMA I } 43 \text {, } \\
\text { sequence tagged site. GEN }=\text { HP PROD = haptoglobin }\end{array}$ & & Up & 3.0 \\
\hline $\begin{array}{l}\text { gi:47777 I } 86 \text { DEF }=\text { THBSI_279 Rhesus macaque genomic DNA Macaca mulatta STS genomic clone } \\
\text { MMA279, sequence tagged site. GEN = THBSI PROD = thrombospondin I }\end{array}$ & & Up & 2.6 \\
\hline Serpin peptidase inhibitor, clade E (nexin, plasminogen activator inhibitor type I), member I & AL574210 & Up & 2.5 \\
\hline ADP-ribosylation factor-like $4 \mathrm{C}$ & AW450363 & Up & 2.1 \\
\hline ARTCI mRNA, complete sequence & $\mathrm{BF} 5088 / 3$ & Up & 2.0 \\
\hline Serine/threonine kinase $17 \mathrm{a}$ & AWI94730 & Up & 2.0 \\
\hline
\end{tabular}

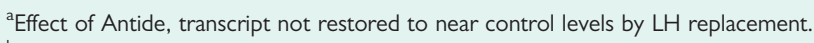

${ }^{\mathrm{b}}$ Control: Antide $+\mathrm{LH}$.

Antide, but R5020 replacement either did not affect mRNA levels (PRLR; Fig. 3B), or only partially maintained mRNA at control levels (SC4MOL; Fig. 3C).
The expression of transcripts for genomic steroid hormone receptors as measured by microarray was low, and the pattern did not change throughout the experimental groups; examples include the 
Table III Ontologies significantly impacted by LH and steroid ablation/replacement ${ }^{\mathrm{a}}$

\begin{tabular}{|c|c|c|c|c|}
\hline Ontology & List & Array & z-score & $\%^{\mathbf{b}}$ \\
\hline \multicolumn{5}{|l|}{ Immune system } \\
\hline immunoglobulin production & 5 & 13 & 6.09 & 38 \\
\hline regulation of $B$ cell activation & 5 & 16 & 5.33 & 31 \\
\hline production of molecular mediator of immune response & 5 & 22 & 4.27 & 23 \\
\hline cellular defense response & 10 & 53 & 5.25 & 19 \\
\hline B cell activation & 8 & 46 & 4.40 & 17 \\
\hline response to inorganic substance & 5 & 29 & 3.45 & 17 \\
\hline leukocyte differentiation & 9 & 71 & 3.50 & 13 \\
\hline immune system development & 13 & 135 & 3.08 & 10 \\
\hline negative regulation of immune system process & 6 & 27 & 4.61 & 22 \\
\hline \multicolumn{5}{|l|}{ Steroid/cholesterol processes/metabolism } \\
\hline sterol biosynthetic process & 11 & 30 & 8.77 & 37 \\
\hline cholesterol biosynthetic process & 8 & 23 & 7.23 & 35 \\
\hline steroid biosynthetic process & 17 & 62 & 9.02 & 27 \\
\hline sterol metabolic process & 16 & 68 & 7.86 & 24 \\
\hline cholesterol metabolic process & 13 & 61 & 6.58 & 21 \\
\hline steroid metabolic process & 26 & 142 & 8.30 & 18 \\
\hline lipid biosynthetic process & 32 & 222 & 7.53 & 14 \\
\hline \multicolumn{5}{|l|}{ Cellular morpohology } \\
\hline regulation of cell shape & 5 & 31 & 3.26 & 16 \\
\hline regulation of cell morphogenesis & 5 & 32 & 3.17 & 16 \\
\hline cell-substrate adhesion & 10 & 70 & 4.14 & 14 \\
\hline myeloid cell differentiation & 8 & 58 & 3.58 & 14 \\
\hline cell-matrix adhesion & 9 & 66 & 3.76 & 14 \\
\hline chemotaxis & 11 & 100 & 3.33 & 11 \\
\hline taxis & 11 & 100 & 3.33 & 11 \\
\hline \multicolumn{5}{|l|}{ Cellular metabolism/biosynthesis } \\
\hline isoprenoid metabolic process & 5 & 25 & 3.88 & 20 \\
\hline oxygen and reactive oxygen species metabolic process & 6 & 31 & 4.15 & 19 \\
\hline water-soluble vitamin metabolic process & 7 & 37 & 4.40 & 19 \\
\hline oxidoreduction coenzyme metabolic process & 5 & 31 & 3.26 & 16 \\
\hline vitamin metabolic process & 8 & 55 & 3.76 & 15 \\
\hline cofactor metabolic process & 15 & 122 & 4.39 & 12 \\
\hline membrane lipid biosynthetic process & 10 & 83 & 3.50 & 12 \\
\hline coenzyme metabolic process & 12 & 100 & 3.82 & 12 \\
\hline alcohol metabolic process & 27 & 228 & 5.69 & 12 \\
\hline cellular lipid metabolic process & 52 & 472 & 7.39 & 11 \\
\hline glycoprotein biosynthetic process & 12 & 110 & 3.45 & II \\
\hline glycoprotein metabolic process & 14 & 131 & 3.64 & II \\
\hline protein amino acid glycosylation & 11 & 103 & 3.22 & II \\
\hline biopolymer glycosylation & 11 & 105 & 3.15 & 10 \\
\hline fatty acid metabolic process & 14 & $|4|$ & 3.33 & 10 \\
\hline isoprenoid biosynthetic process & 5 & 15 & 5.56 & 33 \\
\hline \multicolumn{5}{|l|}{ Signal transduction } \\
\hline activation of phospholipase $C$ activity & 2 & 12 & 2.12 & 17 \\
\hline peptidyl-tyrosine modification & 5 & 36 & 2.85 & 14 \\
\hline positive regulation of I-kappaB kinase/NF-kappaB cascade & 9 & 78 & 3.17 & 12 \\
\hline
\end{tabular}

${ }^{a}$ z-score $\geq 3.0$, as determined by GeneSifter(C) Software Analysis and $\geq 5$ transcripts per ontology, with significant transcripts representing at least $10 \%$ of ontology on array.

b\% determined by number of transcripts in ontology list divided by total number of transcripts in ontology on array. 
Table IV Real-time PCR validation of select differentially expressed genes

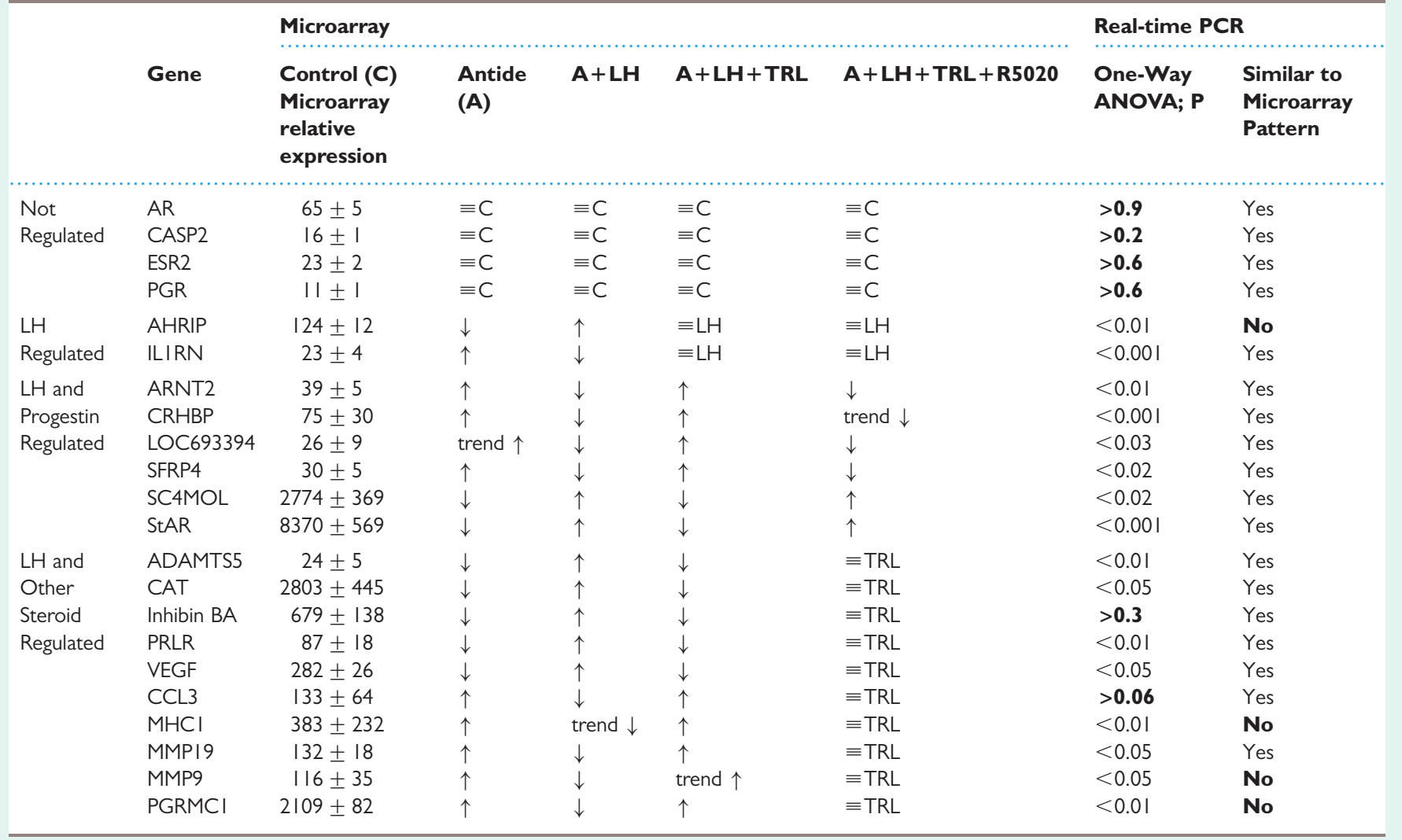

Control values $( \pm$ SEM) are presented as a reference. Direction of expression of validated genes by microarray analysis is compared with previous group (e.g. A compared with C), except for genes whose expression did not differ from control. One-way ANOVA values of significance are presented for real-time PCR validation.

PGR (Table IV and Fig. 4A), the AR and estrogen receptor $\beta$ (AR and ESR2, respectively; Table IV). The only putative steroid hormone receptor whose transcript levels differed significantly with treatment, based on microarray and real-time PCR analyses, was the non-classical progestin receptor: progesterone receptor membrane component I (PGRMCl; Fig. 4B). This transcript was highly expressed, but the pattern of mRNA expression differed between real-time PCR data and the microarray for both $A+L H$ and $A+L H+T R L$ treatment groups (Fig. 4B).

Two gene products, StAR protein and SFRP4, were chosen to determine whether there was any correlation between their mRNA and protein levels. One gene displayed high levels of mRNA expression (StAR; Fig. 5A), whereas expression of mRNA for the other gene was moderate (SFRP4; Fig. 6A). Again, the patterns of expression for mRNA data from real-time PCR matched microarray analysis for both genes. The mRNA levels for StAR were markedly decreased by Antide treatment, but maintained near-control levels by $\mathrm{LH}$ replacement, and comparable results were obtained by TRL treatment and R5020 replacement (Fig. 5A). Notably, the pattern of StAR protein levels between treatment groups was similar to that of mRNA levels (Fig. 5B). In contrast, SFRP4 mRNA levels increased 6-fold with Antide treatment, and replacement of $\mathrm{LH}$ reduced, but did not completely restore mRNA to control levels; TRL treatment with or without $\mathrm{R} 5020$ replacement had a minimal effect when measured by real-time PCR (Fig. 6A). Although the levels of protein for SFRP4 changed significantly across treatment groups (Fig. 6B; $P<0.00 \mathrm{I})$, the expression pattern of the protein did not match that of the mRNA. Protein levels were unchanged between LH ablation and replacement groups, whereas steroid ablation by TRL treatment lowered the expression levels, and R5020 replacement had no further effect. The western blots for pooled samples for StAR and SFRP4 are shown in Fig. 7.

\section{Discussion}

This study provides a genome-wide analysis of macaque luteal transcripts that are either directly or indirectly regulated by LH. All normalized data files have been uploaded to the National Center for Biotechnology Information's Gene Expression Omnibus gene expression repository (http://www.ncbi.nlm.nih.gov/geo/; series GSEI228I), which allows for further analyses to be performed by independent investigators. The current microarray analysis confirmed earlier reports of LH-regulated transcripts in macaque luteal tissue. For example, our preliminary analysis of LH-regulated genes in the macaque $\mathrm{CL}$ from Antide-treated monkeys identified CRHBP mRNA as markedly up-regulated by LH withdrawal ( $\mathrm{Xu}$ et al., 2005). This evidence led to the detailed characterization of a novel local system in the macaque $\mathrm{CL}$ - the $\mathrm{CRH} / \mathrm{UCN}$ receptor-binding protein system - that may modulate $\mathrm{LH}$ action and hence regulate primate luteal structure-function (Xu et al., 2007). The current 

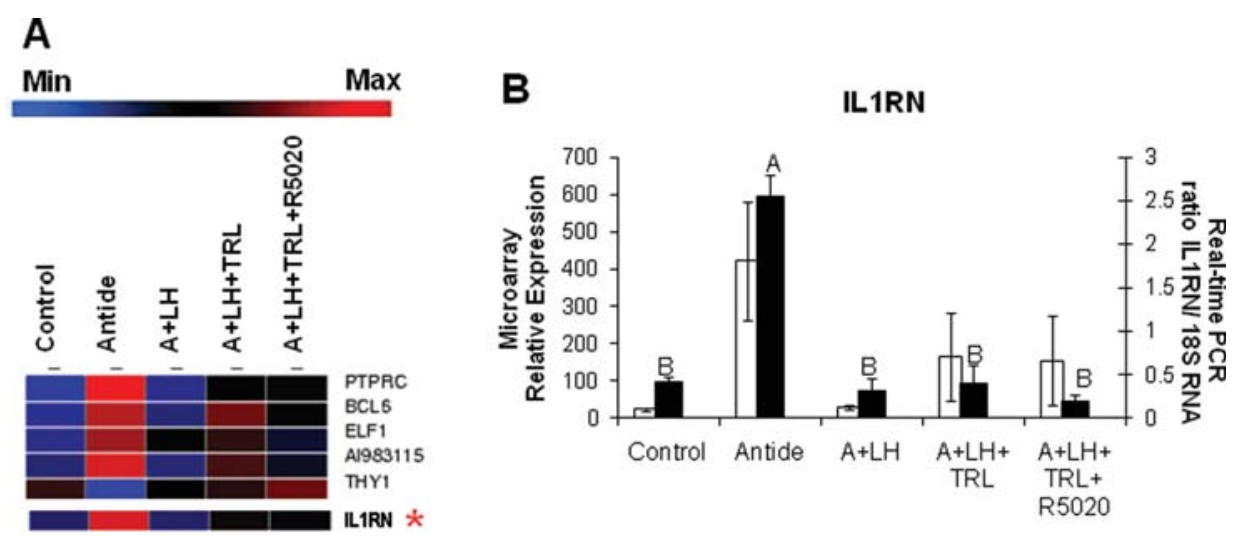

Figure 2 A list of regulated transcripts identified by GeneSifter (C) from the KEGG ontology 'Negative Regulation of Immune System Process' (as in Table III) as significantly (one-way ANOVA, $P<0.05$ ) affected by treatments is shown in Panel $\mathbf{A}$ (blue indicates minimum expression, whereas red indicates maximum). A comparison of interleukin I receptor antagonist (ILIRN; mean \pm SEM) results is depicted in Panel $\mathbf{B}$, with white bars representing microarray values (GeneSifter $(C$ ) one-way ANOVA, $P<0.05$ ), and black bars representing real-time PCR data (one-way ANOVA, $P<0.00$ I; different letters signify treatment groups with significantly different values, $P<0.05$ ).

\section{A}

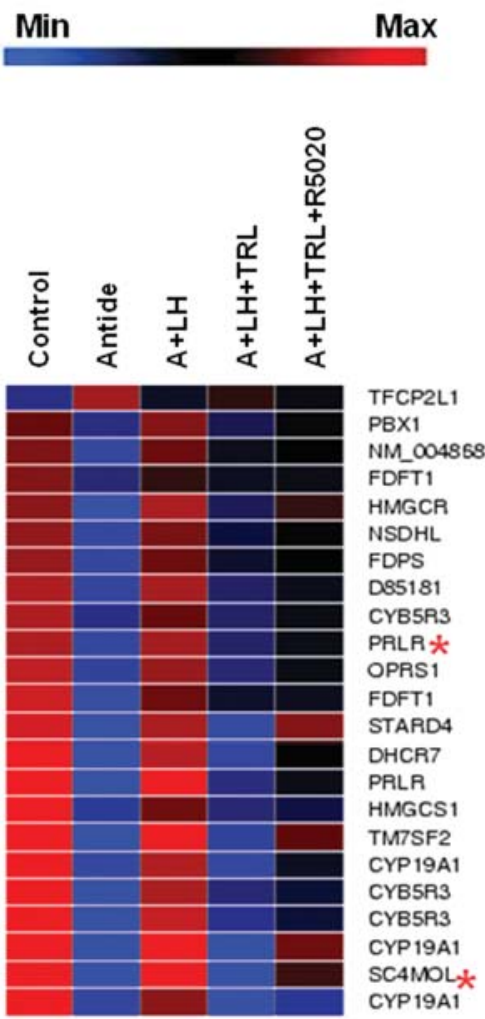

B
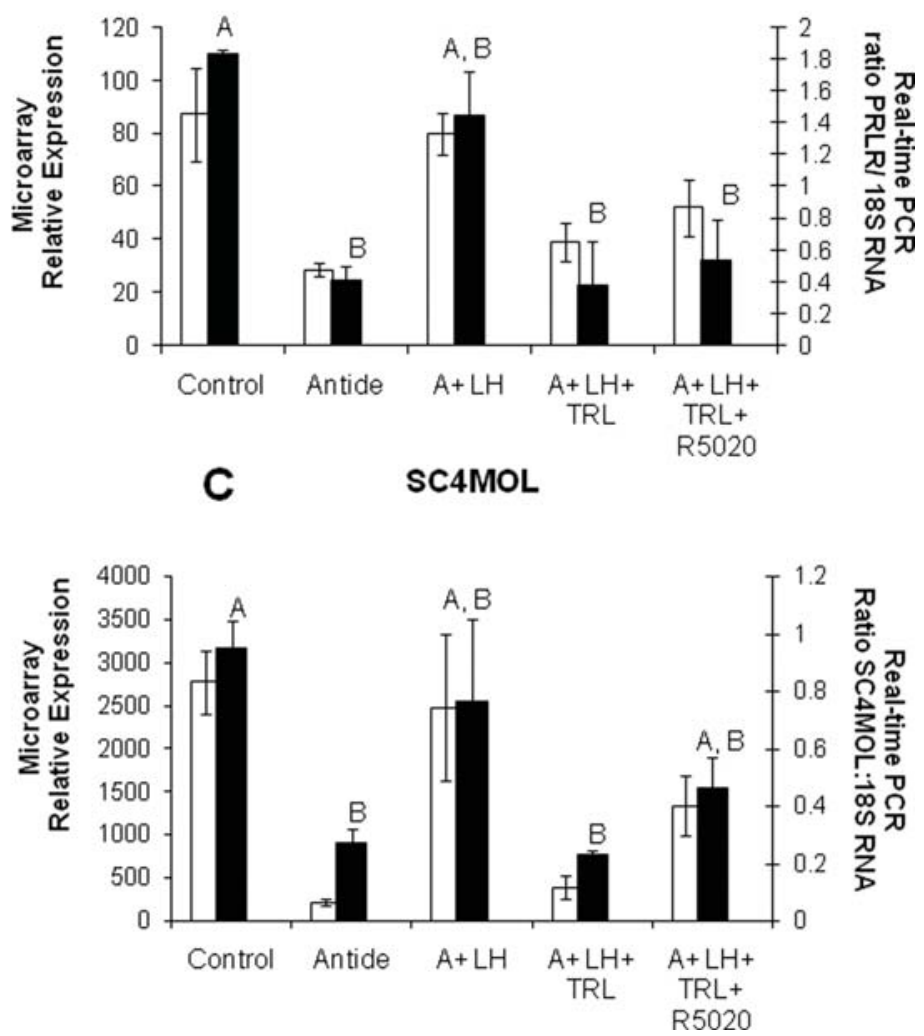

Figure 3 A list of transcripts identified by GeneSifter (C) from the KEGG ontology 'Steroid Biosynthetic Process' (similar to Table III) as significantly (one-way ANOVA, $P<0.05$ ) affected by treatments is shown in Panel $\mathbf{A}$ (blue indicates minimum expression, whereas red indicates maximum expression). The red stars indicate the relative expression of transcripts for the PRLR and SC4MOL. Real-time PCR results for PRLR (Panel B; one-way ANOVA, $P<0.01$ ) and SC4MOL (Panel $\mathbf{C}$; one-way ANOVA, $P=0.0 \mathrm{I}$ ) are compared with microarray results $(P<0.05)$. See the legend of Fig. 2 for more details. 


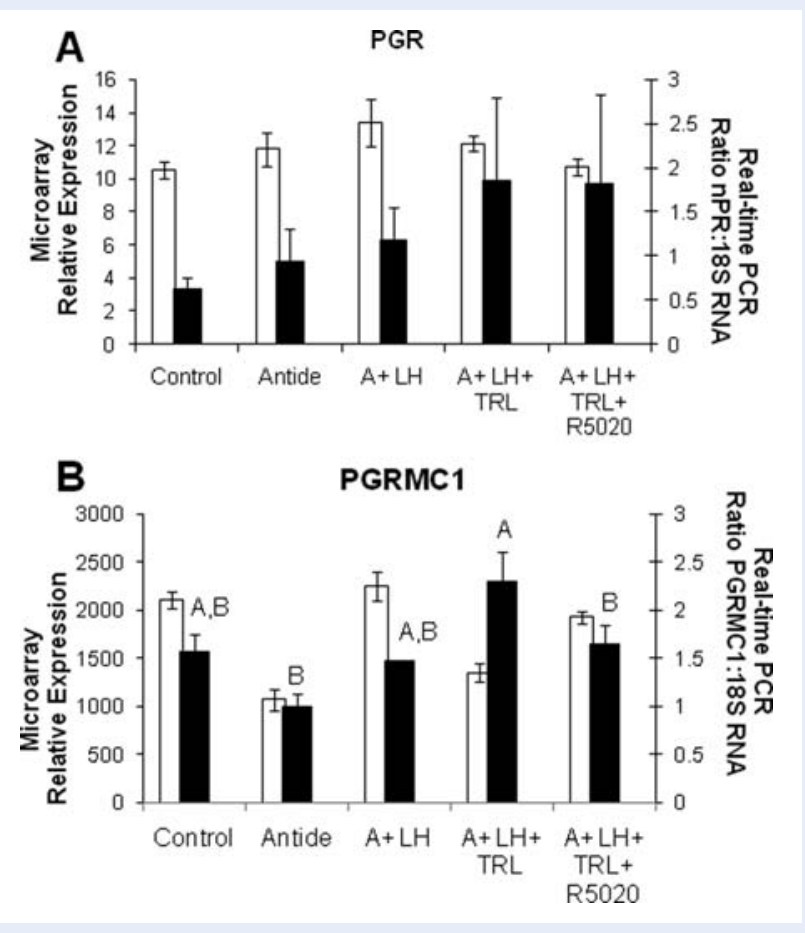

Figure 4 Microarray and real-time PCR expression patterns for the genomic PGR (Panel A; GeneSifter $(C)$ and real-time PCR one-way ANOVA, $P>0.6)$ and $P$ receptor membrane component I (PGRMCI; Panel B; GeneSifter $($ one-way ANOVA, $P<0.05$; realtime PCR one-way ANOVA, $P<0.01$ ). Statistics for $P G R$ and PGRMCI are depicted for real-time PCR results (mean \pm SEM), with white bars representing microarray values, and black bars representing real-time data. Different letters signify treatment groups with significantly different values $(P<0.05)$.

results expand our understanding of the control of CRHBP expression and, possibly, action, with the finding that steroid withdrawal and R5020 replacement mimicked the effects of Antide treatment and $\mathrm{LH}$ replacement. Thus, CRHBP appears indirectly regulated by $\mathrm{LH}$ via steroid hormone production, particularly the local actions of P. Also, the current results confirm and extend the evidence from differential gene display in the bonnet monkey $\mathrm{CL}$ that $\mathrm{LH}$ withdrawal markedly suppressed the expression of LDL receptor mRNA, a key membrane component for cholesterol uptake into primate luteal cells (Yadav et al., 2004).

However, the current analysis also identified many novel transcripts whose expression is $\mathrm{LH}$-regulated in the macaque $\mathrm{CL}$. For example, mRNA for the ILIRN, a suppressor of the immune system, that was first detected in the ovaries of rats (Kol et al., 1999) and later reported to increase interleukin- I $\beta$-stimulated prostaglandin $\left(E, F_{2 \alpha}\right)$ release from human luteal cells (Miceli et al., 2003), was up-regulated by $\mathrm{LH}$ withdrawal. This $\mathrm{LH}$ action appears independent of local steroid action, since LH treatment restored ILIRN mRNA to control levels and steroid withdrawal did not mimic the effect of Antide treatment. Unexpectedly, PRLR mRNA expression in the macaque $\mathrm{CL}$ was down-regulated by $\mathrm{LH}$ withdrawal. Unlike in some non-primate species [e.g. rodents (Herz et al., 1986)], PRL and PRL-like hormones are not considered major luteotropic hormones for the primate $\mathrm{CL}$
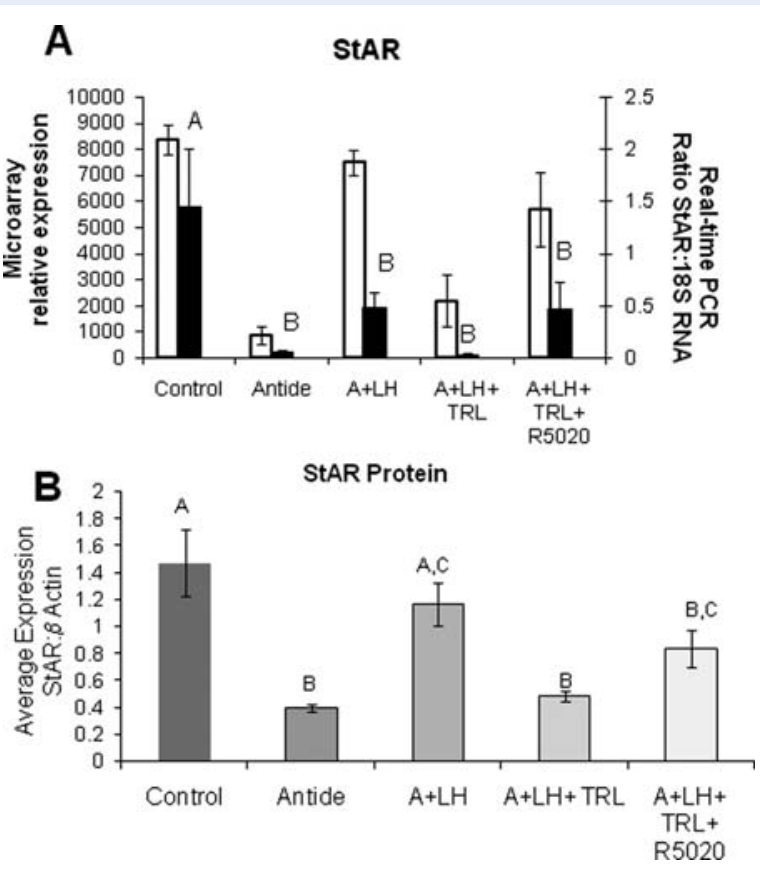

Figure 5 StAR mRNA expression (Panel A; white bars indicate microarray data, black bars indicate real-time data: see the legend of Fig. 2 for more details on microarray and real-time data; one-way ANOVA, $P<0.00 \mathrm{I}$ ) and protein levels (Panel B; one-way ANOVA, $P<0.001$; means \pm SEM) in individual $C L$ normalized to $\beta$-actin as compared between treatment groups.

(Stouffer, 2006). However, a recent microarray analysis (Bogan et al., 2008b) of gene expression in the macaque CL throughout the menstrual cycle discovered appreciable PRLR expression that declined at luteolysis; moreover, the expression pattern for PRLR mRNA and protein were comparable. There are high levels of prolactin (-like) proteins circulating during pregnancy and lactation (Bachelot and Binart, 2007). The possibility proposed by Knobil and colleagues (Richardson et al., 1985) that PRLR ligands could contribute to the maintenance of luteal function in primates, perhaps during pregnancy and lactation, warrants re-evaluation.

Notably, a small but significant number $(n=36$, Fig. IB and Table II) of Antide-sensitive transcripts in the macaque $C L$ were not affected by $\mathrm{LH}$ replacement. Of particular interest is the expression of LDL receptor (discussed earlier), a key component in cholesterol entrance into the cell, and prostaglandin F receptor (PTGFR), a potent, local and perhaps physiologic luteolytic factor in primates (Yadav et al., 2004; Bogan et al., 2008a). Expression of both LDL receptor mRNA and PTGFR declined markedly with Antide treatment, and this effect was not significantly altered by $\mathrm{LH}$ replacement. Although the LH-replacement regimen restored the expression of many Antidesensitive gene products, and this regimen prevents the functionalstructural regression of the $\mathrm{CL}$ in Antide-treated monkeys (Duffy et al., 1999b), it is possible that our LH protocol was sub-optimal for a cohort of LH-regulated genes. Alternatively, there is evidence of GnRH receptor expression (Chakrabarti et al., 2008) and GnRH effects (Siler-Khodr et al., 2004) in primate ovaries and CL. Though it is currently controversial whether $\mathrm{GnRH}$ serves as an important 


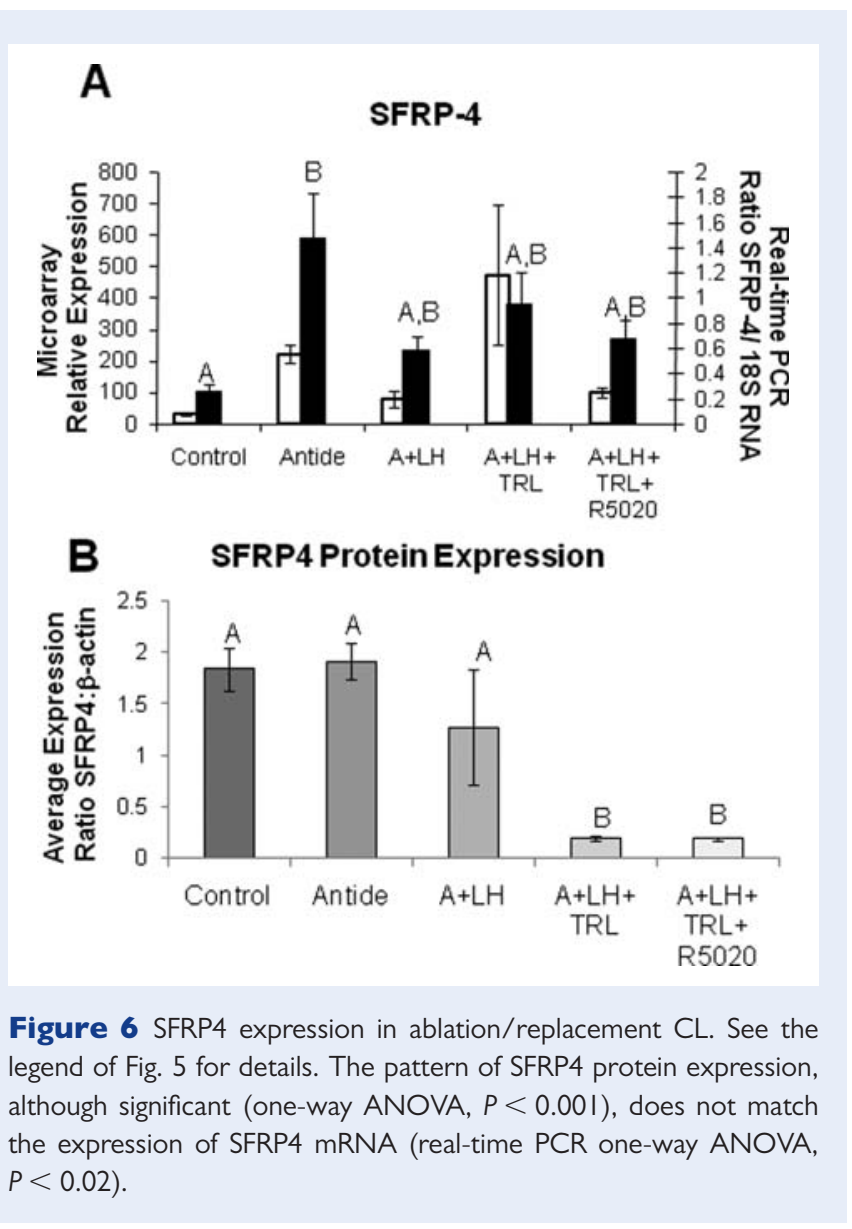

local factor in primates, as it does in rodents (Gupta and Flaws, 2005), we cannot rule out that Antide affects luteal $\mathrm{GnRH}$ signaling and action. Indeed, the Antide-sensitive, LH-insensitive gene products could be markers of local $\mathrm{GnRH}$ action in the primate $\mathrm{CL}$.

Of the approaching $1500 \mathrm{LH}$-sensitive transcripts in the macaque $\mathrm{CL}$, less than one-third of this cohort was affected similarly by steroid ablation, and even fewer by progestin replacement (Fig. IB). This evidence implies that many $\mathrm{LH}$-regulated genes are independent of steroid action; their expression may be regulated directly by $\mathrm{LH}$ signaling pathways, or indirectly by other LH-regulated local factors (e.g. $\mathrm{CRH} / \mathrm{UCN}$, VEGF, PGs) or LH-regulated receptors/binding proteins for other hormones or local factors (PRLR, CRHBP) in the CL. That progestin replacement only restored transcript levels for some genes may again (as for $\mathrm{LH}$ replacement) be a limitation of our R5020 regimen. Nevertheless, this regimen prevents endocrine and histological indices of functional and structural luteolysis (Young and Stouffer, 2004), in the macaque $C L$, and unequivocally restored mRNA levels of select steroid-sensitive genes (see what follows). It is possible that the numbers or types of cells expressing some of these steroidsensitive transcripts changed after 3 days of treatment. Previous histological analyses of Antide- and $\mathrm{A}+\mathrm{LH}+\mathrm{TRL}$-treated $\mathrm{CL}$ revealed that steroidogenic cells were smaller in volume, and the numbers of immune cells were greater, compared with control, $\mathrm{A}+\mathrm{LH}$ and $\mathrm{A}+$ $\mathrm{LH}+\mathrm{TRL}+\mathrm{R} 5020$ treatments (Young and Stouffer, 2004); but these observations were qualitative. Alternatively, it is possible that by mid-late luteal phase (Day $9-12$ ), the $C L$ is not as responsive to

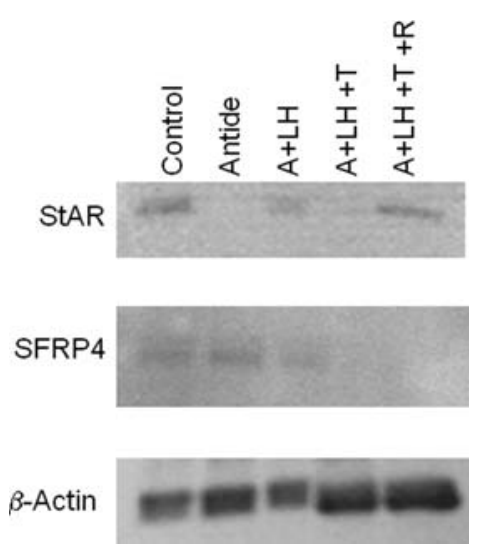

Figure 7 Representative immunoblots for StAR, SFRP4 and $\beta$-actin loading control for pooled samples of different treatment groups. Note that as presented in Fig. 5A and B, StAR protein expression matches mRNA expression patterns, whereas SFRP4 protein expression does not match mRNA expression. $\beta$-Actin was used for loading control.

progestin as luteal tissue from the early-to-mid-luteal phase. We reported previously that the percent of PR-positive cells and PR mRNA levels in the macaque CL decline after mid-luteal phase (HildPetito et al., 1988; Duffy et al., 1999b). Moreover, there is evidence that gene expression in the $C L$ in response to steroid withdrawal and progestin replacement differs between the early and mid-late luteal phase [e.g. ADAMTS-I, a disintegrin and metalloproteinase with thrombospondin repeats-I (Young et al., 2004)]. This differential response could also be related to changes in the ratio of $P R A: B$ isoforms as the luteal lifespan progresses (Duffy et al., 1997). The current analysis also detected appreciable mRNA levels for the novel membrane progestin receptor PGRMCI in macaque luteal tissue. A physiologic role for $\mathrm{PGRMCI}$ in the $\mathrm{CL}$ has yet to be defined, but it could play a role in mediating the $\mathrm{LH}$-like, luteotropic effects of $\mathrm{P}$ by preventing apoptosis of luteinized cells (Engmann et al., 2006). Finally, since the $3 \beta-H S D$ inhibitor, TRL, markedly suppresses production of other steroids relying on $\mathrm{P}$ as a precursor, those steroid-sensitive transcripts that were not restored by $\mathrm{R} 5020$ replacement could be altered by androgen or estrogen withdrawal. The macaque $C L$ expresses $A R$ and ER (particularly ER $\beta$ ) during its lifespan (Duffy et al., 1999a, 2000). Moreover, Duffy et al. (2000) reported that ER $\beta$ mRNA levels decreased around luteolysis and that steroid withdrawal at mid-luteal phase (Day 6) increased ER $\beta$ expression, whereas R5020 replacement returned expression to control levels. Further studies are needed at earlier stages of luteal development and function, and while replacing estrogen or androgen, as well as progestin, to clarify the LH- and steroid-regulated gene processes in the primate $\mathrm{CL}$.

Nevertheless, the changes in mRNA levels of several genes in response to $\mathrm{LH}$ withdrawal and replacement were mimicked by steroid withdrawal and progestin replacement. For example, StAR expression exhibited a similar pattern following either withdrawal/ replacement regimen (Fig. 5), strongly suggesting that the changes evoked by $\mathrm{LH}$ were indirect and are due to $\mathrm{LH}$-stimulated $\mathrm{P}$ production by the tissue. Abundant levels of StAR protein are expressed 
in the developing and developed human $\mathrm{CL}$, and these levels decline between the mid- and late-luteal phase (Devoto et al., 200I). Likewise, expression of other enzymes in the ontology 'steroid biosynthetic processes' (Fig. 3), SC4MOL and CYPI9AI, exhibited a similar pattern following either $\mathrm{LH}$ or steroid withdrawal/replacement regimen. Thus, $\mathrm{P}$ may regulate a select number of key genes that are critical for luteal structure-function around the onset of luteolysis at mid-late luteal phase. As noted from our initial analyses of mRNA and protein levels, it will be important to follow genomic analyses with evaluations of the translation and activity of gene products. The patterns of mRNA and protein expression were similar for StAR, suggesting that transcriptional regulation is a key part of progestin regulation of StAR production. However, the patterns of mRNA and protein levels for secreted frizzled related protein 4 (SFRP4) were not comparable, suggesting that regulation of SFRP4 can occur at the translational level. This concept is consistent with previous evidence (Young and Stouffer 2004; Peluffo et al., 2005) that LH/progestin regulation of proteases (caspases, MMPs) can occur at either/both the mRNA, protein or enzyme activity level. Further analysis of the actions of $\mathrm{LH}$ and steroids at the transcriptional, translational and post-translational levels is needed to understand the regulation of luteal structure-function in primates.

In summary, this microarray experiment broadly defines the changes in gene expression in the primate $\mathrm{CL}$ that are regulated by $\mathrm{LH}$ around the onset of luteolysis in the menstrual cycle. The data suggest that $\mathrm{LH}$ regulates the expression of many genes involved in the maintenance of $C L$ structure-function independently of steroid action. However, steroid withdrawal and R5020 replacement indicate that progestin is involved in the regulation of key pathways that regulate the CL lifespan (Stouffer, 2003), and this may involve actions via a non-classical PR. Also, steroid-sensitive genes whose activity was not restored by $\mathrm{R} 5020$ replacement could be regulated by androgens or estrogens. Further studies on LH/steroid withdrawal and replacement during $\mathrm{CL}$ development in the early-luteal phase and analysis of the patterns of both mRNA and protein expression in macaque $\mathrm{CL}$ are needed. During revision of this manuscript, a microarray analysis of a limited sample of primate CL after short-term LH ablation was published online (Priyanka et al., 2008). Comparisons of similar studies will help to elucidate the relative roles of $\mathrm{LH}$ and steroids on gene expression in the primate $\mathrm{CL}$ during the menstrual cycle.

\section{Acknowledgements}

The authors are indebted to Dr Kelly Young for establishing the dosage paradigm, collecting the $C L$ and processing $C L$ for mRNA. We also thank Dr Marina Peluffo for processing $C L$ for protein. We acknowledge the critical expertise of the staff in the Division of Animal Resources, ONPRC for their animal caretaking and assistance with treatment protocols, and especially the surgery staff for their role in the collection of ovarian tissues.

\section{Funding}

This work was supported by several grants from the National Institutes of Health (NIH) [ROI HD20869 to R.L.S., ROI HD42000 to J.D.H., U54 HDI8I85 (Molecular and Cellular Biology Core), P5I
RR00163]; plus a National Research Service Award (NRSA) Institutional Fellowship [T32 HD007I33 to CVB].

\section{References}

Ascoli M, Fanelli F, Segaloff DL. The lutropin/choriogonadotropin receptor, a 2002 perspective. Endocr Rev 2002;23: I4 I- 174.

Bachelot A, Binart N. Reproductive role of prolactin. Reproduction 2007; I33:36I-369.

Benyo DF, Zeleznik AJ. Cyclic adenosine monophosphate signaling in the primate corpus luteum: maintenance of protein kinase $A$ activity throughout the luteal phase of the menstrual cycle. Endocrinology 1997; | 38:3452-3458.

Bogan RL, Murphy MJ, Stouffer RL, Hennebold JD. Prostaglandin synthesis, metabolism, and signaling potential in the rhesus macaque corpus luteum throughout the luteal phase of the menstrual cycle. Endocrinology 2008a; | 49:586 I-587|.

Bogan RL, Murphy MJ, Stouffer RL, Hennebold JD. Systematic determination of differential gene expression in the primate corpus luteum during the luteal phase of the menstrual cycle. Mol Endocrinol 2008b;22:1260- 1273.

Chakrabarti N, Subbarao T, Sengupta A, Xu F, Stouffer RL, Sridaran R. Expression of mRNA and proteins for $\mathrm{GnRH} \mathrm{I}$ and II and their receptors in primate corpus luteum during menstrual cycle. Mol Reprod Dev 2008;75: I567-I577.

Devoto L, Kohen P, Gonzalez RR, Castro O, Retamales I, Vega M, Carvallo P, Christenson LK, Strauss JF III. Expression of steroidogenic acute regulatory protein in the human corpus luteum throughout the luteal phase. J Clin Endocrinol Metab 200I;86:5633-5639.

Doniger SW, Salomonis N, Dahlquist KD, Vranizan K, Lawlor SC, Conklin BR. MAPPFinder: using Gene Ontology and GenMAPP to create a global gene-expression profile from microarray data. Genome Biol 2003;4:R7.

Duffy DM, Hess DL, Stouffer RL. Acute administration of a 3 beta-hydroxysteroid dehydrogenase inhibitor to rhesus monkeys at the midluteal phase of the menstrual cycle: evidence for possible autocrine regulation of the primate corpus luteum by progesterone. J Clin Endocrinol Metab 1994;79:1587-1594.

Duffy DM, Wells TR, Haluska G], Stouffer RL. The ratio of progesterone receptor isoforms changes in the monkey corpus luteum during the luteal phase of the menstrual cycle. Biol Reprod 1997;57:693-699.

Duffy DM, Abdelgadir SE, Stott KR, Resko JA, Stouffer RL, Zelinski-Wooten MB. Androgen receptor mRNA expression in the rhesus monkey ovary. Endocrine 1999a; I I:23-30.

Duffy DM, Stewart DR, Stouffer RL. Titrating luteinizing hormone replacement to sustain the structure and function of the corpus luteum after gonadotropin-releasing hormone antagonist treatment in rhesus monkeys. J Clin Endocrinol Metab 1999b;84:342-349.

Duffy DM, Chaffin CL, Stouffer RL. Expression of estrogen receptor alpha and beta in the rhesus monkey corpus luteum during the menstrual cycle: regulation by luteinizing hormone and progesterone. Endocrinology 2000; 141:1711-1717.

Engmann L, Losel R, Wehling M, Peluso JJ. Progesterone regulation of human granulosa/luteal cell viability by an RU486-independent mechanism. J Clin Endocrinol Metab 2006;91:4962-4968.

Gupta RK, Flaws JA. Gonadotropin-releasing hormone $(\mathrm{GnRH})$ analogues and the ovary: do $\mathrm{GnRH}$ antagonists destroy primordial follicles? Fertil Steril 2005;83: 1339-1342.

Herz Z, Khan I, Jayatilak PG, Gibori G. Evidence for the secretion of decidual luteotropin: a prolactin-like hormone produced by rat decidual cells. Endocrinology 1986; I 1 8:2203-2209. 
Hild-Petito S, Stouffer RL, Brenner RM. Immunocytochemical localization of estradiol and progesterone receptors in the monkey ovary throughout the menstrual cycle. Endocrinology 1988; I 23:2896-2905.

Kol S, Donesky BW, Ruutiainen-Altman K, Ben-Shlomo I, Irahara M, Ando M, Rohan RM, Adashi EY. Ovarian interleukin-I receptor antagonist in rats: gene expression, cellular localization, cyclic variation, and hormonal regulation of a potential determinant of interleukin-I action. Biol Reprod 1999;61:274-282.

Lonard DM, O'Malley BW. Expanding functional diversity of the coactivators. Trends Biochem Sci 2005;30:126-132.

Miceli F, Tropea A, Minici F, Navarra P, Lanzone A, Apa R. Interleukin-I beta stimulates progesterone production by in vitro human luteal cells: evidence of a mediatory role of prostaglandins. J Clin Endocrinol Metab 2003;88:2690-2694.

Molskness TA, Zelinski-Wooten MB, Hild-Petito SA, Stouffer RL. Comparison of the steroidogenic response of luteinized granulosa cells from rhesus monkeys to luteinizing hormone and chorionic gonadotropin. Biol Reprod 1991;45:273-28I.

Noriega NC, Garyfallou VT, Kohama SG, Urbanski HF. Glutamate receptor subunit expression in the rhesus macaque locus coeruleus. Brain Res 2007; I 1 73:53-65.

Parent AS, Matagne V, Westphal M, Heger S, Ojeda S, Jung H. Gene expression profiling of hypothalamic hamartomas: a search for genes associated with central precocious puberty. Horm Res 2008;69: I I4- 123.

Peluffo MC, Young KA, Stouffer RL. Dynamic expression of caspase-2, -3, -8 , and -9 proteins and enzyme activity, but not messenger ribonucleic acid, in the monkey corpus luteum during the menstrual cycle. J Clin Endocrinol Metab 2005;90:2327-2335.

Priyanka S, Medhamurthy R. Characterization of CAMP/PKA/CREB signaling cascade in the bonnet monkey corpus luteum: expressions of inhibin-alpha and StAR during different functional status. Mol Hum Reprod 2007; I3:38I-390.

Priyanka S, Jayaram P, Sridaran R, Medhamurthy R. Genome-wide gene expression analysis reveals a dynamic interplay between luteotropic and luteolytic factors in the regulation of corpus luteum function in the bonnet monkey (Macaca radiata). Endocrinology 2008; 6 November Epub PMID I8988674.

Richardson DW, Goldsmith LT, Pohl CR, Schallenberger E, Knobil E. The role of prolactin in the regulation of the primate corpus luteum. J Clin Endocrinol Metab 1985;60:50I-504.

Rothchild I. The regulation of the mammalian corpus luteum. Recent Prog Horm Res 1981;37:183-298.

Siler-Khodr TM, Yu FQ, Wei P, Tao SX, Liu YX. Contraceptive action of a gonadotropin-releasing hormone II analog in the rhesus monkey. J Clin Endocrinol Metab 2004;89:45।3-4520.

Spindel ER, Pauley MA, Jia Y, Gravett C, Thompson SL, Boyle NF, Ojeda SR, Norgren RB Jr. Leveraging human genomic information to identify nonhuman primate sequences for expression array development. BMC Genomics 2005;6:160.

Stouffer RL. Progesterone as a mediator of gonadotrophin action in the corpus luteum: beyond steroidogenesis. Hum Reprod Update 2003; 9:99- 117

Stouffer RL. Structure, function, and regulation of the corpus luteum. In: Knobil E, Neill JD (eds). Knobil and Neill's Physiology of Reproduction. Amsterdam, Boston: Elsevier, 2006, 475-526.

Stouffer RL, Duffy DM. Receptors for sex steroids in the primate corpus luteum. New insight into gonadotropin and steroid action. Trends Endocrinol Metab 1995;6:83-89.

Tesone M, Stouffer RL, Borman SM, Hennebold JD, Molskness TA. Vascular endothelial growth factor (VEGF) production by the monkey corpus luteum during the menstrual cycle: isoform-selective messenger RNA expression in vivo and hypoxia-regulated protein secretion in vitro. Biol Reprod 2005;73:927-934.

Xu J, Stouffer RL, Searles RP, Hennebold JD. Discovery of LH-regulated genes in the primate corpus luteum. Mol Hum Reprod 2005; II: $15 \mid-159$.

Xu J, Hennebold JD, Stouffer RL. Dynamic expression and regulation of the corticotropin-releasing hormone/urocortin-receptor-binding protein system in the primate ovary during the menstrual cycle. J Clin Endocrinol Metab 2006;9 I:I544-I553.

Xu J, Xu F, Hennebold JD, Molskness TA, Stouffer RL. Expression and role of the corticotropin-releasing hormone/urocortin-receptor-binding protein system in the primate corpus luteum during the menstrual cycle. Endocrinology 2007; | 48:5385-5395.

Yadav VK, Muraly P, Medhamurthy R. Identification of novel genes regulated by $\mathrm{LH}$ in the primate corpus luteum: insight into their regulation during the late luteal phase. Mol Hum Reprod 2004; 10:629-639.

Young KA, Stouffer RL. Gonadotropin and steroid regulation of matrix metalloproteinases and their endogenous tissue inhibitors in the developed corpus luteum of the rhesus monkey during the menstrual cycle. Biol Reprod 2004;70:244-252.

Young KA, Hennebold JD, Stouffer RL. Dynamic expression of mRNAs and proteins for matrix metalloproteinases and their tissue inhibitors in the primate corpus luteum during the menstrual cycle. Mol Hum Reprod 2002;8:833-840.

Young KA, Tumlinson B, Stouffer RL. ADAMTS-I/METH-I and TIMP-3 expression in the primate corpus luteum: divergent patterns and stage-dependent regulation during the natural menstrual cycle. Mol Hum Reprod 2004; 10:559-565.

Zeleznik AJ, Somers JP. Regulation of the primate corpus luteum: cellular and molecular perspectives. Trends Endocrinol Metab 1999; 10:189-193.

Submitted on October 13, 2008; resubmitted on January 13, 2009; accepted on January 2I, 2009 